\title{
IDENTIFIKASI JENIS CACAT KAYU BULAT JATI (Tectona grandis Linn. F.) PADA AREAL PEMANENAN DI KPH JEMBER
}

\author{
(Identification The Types Of Teak (Tectona Grandis Linn. F.) Defects In The Harvesting Area \\ In Kph Jember)
}

\author{
Afthony Ardhiansyah, Gusti Eva Tavita, Iskandar \\ Fakultas Kehutanan Universitas Tanjungpura Pontianak. Jl. Daya Nasional Pontianak 78124 \\ Email: afthony@student.untan.ac.id
}

\begin{abstract}
Teak trees are high-quality plants. The activity of harvesting teak doesn't always produce good quality or without defects found.Various types of defects will reduce the quality and selling value of wood.The purpose of this research was to identify and measure the defects of teak roundwood (Tectona grandis) in the harvesting area in KPH Jember. Knowing the type and quantity of defects is expected to be a reference for companies, especially Perum Perhutani, $K P H$ Jember on process of maintaining teak trees during harvesting, get better results and higher value results. The method that was used in this research was quantitative descriptive research and go to the research site.Sampling is done bypurposive sampling. The research was conducted in March - April 2018. The results of the identification of teak defects (Tectona grandis Linn.F.) found 23 types of defects that was form defects, body defects, or bontos defects. The type of defect found is straightness, cylindrical, backwardness, groove defects, direction of fiber defects, inger-inger, buncak-buncak, hole gerek, broken defects, hole in the body, wood eye, lump defects, lengar defects, broken up defects, slemper defects, bontos defects, fragile terrace, rotten terrace, hole defects, gubal defects, pakah defects, gabeng defects, dan kunus defects. The most defects were the type of buncak-buncak light as 89 trees (98.89\%) and 566 sortiment (56.39\%) that having defects, while the least defect were type of big hole gerek as 2 trees $(2.22 \%)$ and 3 sortiment $(0.30 \%)$ that having defects.
\end{abstract}

Keywords : defect, harvesting, identification, perhutani, teak.

PENDAHULUAN

Tanaman jati (Tectona grandis Linn. F. ) merupakan kayu yang memiliki berat jenis antara 0,62- 0,75 dengan kelas kuat II dan kelas awet I (Sumarna, 2001). Jati banyak diperlukan untuk bahan bangunan maupun barang kerajinan. Produk yang dihasilkan dari bahan dasar jati memiliki harga jual yang tinggi. Pertumbuhan tanaman jati untuk menghasilkan kayu yang berkualitas tinggi harus dilakukan melalui seleksi dan pengujian. Hal ini sangat dipengaruhi oleh perlakuan $\begin{array}{llr}\text { pemeliharaan } & \text { yaitu } & \text { pemupukan, } \\ \text { pembersihan } & \text { tanaman } & \text { bawah, } \\ \text { penjarangan, } & \text { pemangkasan } & \text { dan }\end{array}$ penyemprotan hama atau penyakit. Apabila perlakuan-perlakuan tersebut intensif diterapkan maka pertumbuhan tanaman akan optimal (Umarella dan Sedek, 2011).

Ketika pertumbuhan tanaman jati sudah maksimal dan sudah memasuki waktu panen maka akan diadakan kegiatan penebangan. Kegiatan penebangan merupakan kegiatan sub sistem dari 
kegiatan pemanenan. Kegiatan pemanenan dapat berpotensi menimbulkan kerusakan (cacat) terhadap kayu yang diproduksi, jika pelaksanaan kegiatan tersebut tidak dilakukan dengan baik.

Kegiatan pemanenan jati pada KPH Jember tidak selamanya menghasilkan kualitas kayu yang bagus atau tanpa ditemukanya cacat sama sekali. Tidak jarang pada saat kegiatan pemanenan dijumpai berbagai jenis cacat, baik cacat secara alami pada saat pertumbuhan tanaman atau cacat yang disebabkan karena penebangan dan pembagian batang atau biasa disebut cacat teknis. Oleh sebab itu maka perlu dilakukan penelitian terkait jenis cacat dan ukuran cacat pada tanaman jati.

Cacat merupakan suatu kelainan yang terdapat pada kayu sehingga bisa mempengaruhi mutu dan isi kayu. Cacat yang terdapat pada tanaman jati bisa terjadi secara alami maupun secara teknis, cacat secara teknis yaitu bisa terjadi pada saat penebangan dan pembagian batang. Jenis cacat alami yaitu seperti gerowong atau busuk hati, gubal busuk, inger-inger, buncak-buncak, dll. Sedangkan cacat teknis yaitu seperti pecah banting, pecah slemper, kunus, dll (BSN, 2010a).

Berbagai bentuk jenis cacat akan mengurangi kualitas dan nilai jual kayu. Jenis-jenis dan kuantitas cacat kayu perlu dikenali dan diukur agar dapat diketahui besarnya potensi penurunan kualitas pemanenan yang dihasilkan. Dengan diketahuinya jenis dan kuantitas cacat diharapkan bisa menjadi acuan perusahaan khususnya Perum Perhutani KPH Jember dalam proses pemeliharaan tanaman jati serta pada saat pemanenan, sehingga bisa didapatkan hasil yang lebih baik dan bernilai tinggi.

Tujuan dari penelitian ini adalah untuk mengidentifikasi dan mengukur jenis cacat kayu bulat jati (Tectona grandis Linn. F.) yang terdapat pada areal pemanenan di KPH Jember. Hasil penelitian ini diharapkan dapat menyampaikan data dan informasi kondisi kayu jati terutama kondisi cacat pada kayu bulat jati, yang selanjutnya dapat digunakan sebagai bahan pertimbangan dalam menentukan kualitas kayu jati yang lebih baik dan bernilai tinggi.

\section{METODE PENELITIAN}

Pengambilan data dilakukan pada areal pemanenan di KPH Jember pada bulan Maret - April 2018. Identifikasi cacat kayu bulat jati (Tectona grandis Linn. F.) dilakukan dengan menggunakan metode deskriptif kuantitatif dengan turun langsung dilapangan. Penelitian deskriptif merupakan penelitian yang bertujuan menggambarkan suatu variabel penelitian (Sugiono, 2003). Metode deskriptif kuantitatif menggambarkan deskripsi penjelasan dan gambaran mengenai datadata kuantitatif yang digunakan dalam analisis yang dilakukan (Habibi, 2013).

Menurut Fraenkel dan Wallen (1993) besar sampel minimal bagi penelitian deskriptif sebanyak 100 sampel, penelitian korelasional sebanyak 50 sampel, penelitian kausal perbandingan 30 sampel setiap kelompok dan bagi penelitian eksperimental sebanyak 30 atau 15 sampel. Jumlah sampel yang berhasil diambil sebanyak 90 sampel pohon yang dipanen pada areal pemanenan KPH 
Jember pada bulan Maret sampai April 2018. Pengambilan sampel dilakukan secara purposive sampling. Sampel yang diambil dalam penelitian ini adalah tanaman jati setelah ditebang dengan diameter $30 \mathrm{~cm}$ ke atas pada areal pemanenan di KPH Jember. Analisis data yang digunakan mengacu perhitungan penentuan mutu dan cara uji berdasarkan SNI 7534.2:2010 dan SNI 7535.2:2010 (BSN, 2010b, 2010c).

Pengukuran dilakukan setelah pohon rebah dan setelah pembagian batang, pengukuran dilakukan untuk menentukan dimensi kayu antara lain diameter, panjang dan identifikasi cacat yang terdapat pada kayu. Pengukuran terhadap karakteristik cacat diukur sesuai Standar Nasional Indonesia (SNI) dengan ketentuan pengujian kualitas kayu bulat Jati ( Tectona grandis Linn.F ) yaitu menggunakan acuan SNI 7534.2-2010 dan SNI 7535.2-2010 (BSN, 2010b, 2010c). Parameter cacat yang akan diamati antara lain Jenis cacat, kedalaman cacat, letak, jumlah, dan diameter cacat.

\section{HASIL DAN PEMBAHASAN}

Hasil penelitian dilapangan mengenai cacat kayu bulat jati (Tectona grandis Linn.F.) pada areal pemanenan di $\mathrm{KPH}$ Jember berhasil diidentifikasi sebanyak 90 pohon dengan jumlah sortimen kayu bundar sebanyak 986 sortimen. Hasil pengukuran diperoleh dbh pohon rata-rata sebesar 37,63 cm, diameter ujung sortimen kayu bundar rata-rata sebesar 22,07 cm, dan panjang rata-rata sortimen kayu bundar sebesar 148,87 cm. Berdasarkan kelas sortimen kayu bundar kayu bundar diperoleh sortimen kayu bundar kelas A.I $(\mathrm{d}<20 \mathrm{~cm})$ sebanyak 429 sortimen kayu bundar (43,5\%), kelas A.II $(\mathrm{d}=20 \mathrm{~cm}$ sampai $29 \mathrm{~cm}$ ) sebanyak 369 sortimen kayu bundar $(37,4 \%)$, dan sortimen kayu bundar A.III ( $\mathrm{d} \geq 30 \mathrm{~cm})$ sebanyak 188 sortimen kayu bundar (19,1\%).

Hasil identifikasi cacat kayu bulat jati (Tectona grandis Linn.F.) ditemukan sebanyak 23 jenis cacat baik itu cacat bentuk, cacat badan, maupun cacat bontos. Jenis cacat pada cacat bentuk ada 5 jenis cacat yaitu cacat kelurusan, cacat kesilindrisan, cacat kebundaran, cacat alur,dan cacat arah serat. Jenis cacat pada cacat badan ada 10 jenis cacat yaitu cacat inger-inger, cacat buncak-buncak, cacat lubang gerek, cacat pecah, cacat gerowong di badan, cacat mata kayu, cacat benjolan, cacat lengar, cacat pecah banting, dan pecah slemper, sedangkan pada cacat bontos ada 8 jenis cacat yaitu cacat pecah bontos, cacat teras rapuh, cacat teras busuk, cacat gerowong, cacat gubal, cacat pakah, cacat gabeng, dan cacat kunus. Jumlah tiap jenis cacat kayu bulat jati (Tectona grandis Linn.F.) dapat dilihat pada Tabel 1. 
Tabel 1. Jenis dan Jumlah Cacat Kayu Bulat Jati (Tectona grandis Linn.F.) pada Areal Pemanenan di KPH Jember (Type and Totals of Teak (Tectona grandis Linn. F.) in the Harvesting Area in KPH Jember)

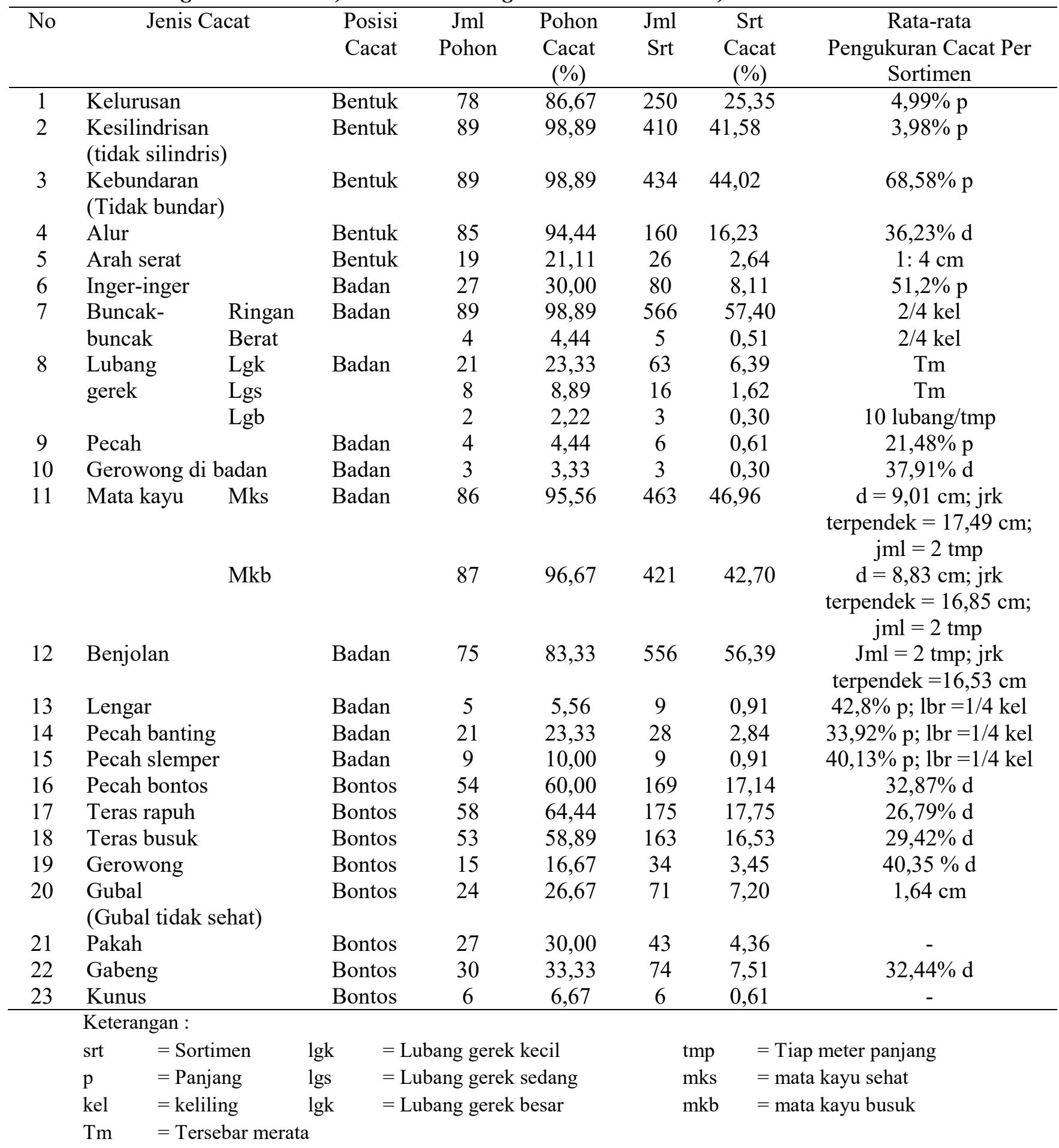


Hasil Tabel 1 mengenai jenis dan jumlah cacat kayu bulat jati (tectona grandis Linn.F.) pada areal pemanenan di KPH Jember, ditemukan cacat bentuk terbanyak yaitu jenis cacat kebundaran (tidak bundar) dengan jumlah pohon sebanyak 89 pohon $(98,89 \%)$ dan sortimen kayu bundar sebanyak 434 sortimen kayu bundar $(44,02 \%)$ yang mengalami cacat, sedangkan cacat bentuk paling sedikit yaitu jenis cacat arah serat dengan jumlah pohon sebanyak 19 pohon $(21,11 \%)$ dan sortimen kayu bundar sebanyak 26 sortimen kayu bundar (2,64\%) yang mengalami cacat. Cacat pada badan terbanyak yaitu jenis cacat buncak-buncak ringan dengan jumlah pohon sebanyak 89 pohon $(98,89 \%)$ dan sortimen kayu bundar sebanyak 566 sortimen kayu bundar $(57,4 \%)$ yang mengalami cacat, sedangkan cacat pada badan paling sedikit yaitu jenis cacat lubang gerek besar (Lgb) dengan jumlah pohon sebanyak 2 pohon dan sortimen kayu bundar sebanyak 3 sortimen kayu bundar. Cacat pada bontos terbanyak yaitu jenis cacat teras rapuh dengan jumlah pohon sebanyak 58 pohon $(64,44 \%)$ dengan jumlah sortimen kayu bundar sebanyak 175 sortimen kayu bundar $(17,75 \%)$ yang mengalami cacat, sedangkan cacat pada bontos paling sedikit yaitu jenis cacat kunus dengan jumlah pohon sebanyak 6 pohon $(6,67 \%)$ dengan jumlah sortimen kayu bundar sebanyak 6 sortimen kayu bundar $(0,61 \%)$ yang mengalami cacat.

Secara keseluruhan cacat terbanyak yaitu jenis cacat buncak-buncak ringan dengan jumlah pohon sebanyak 89 pohon $(98,89 \%)$ dan sortimen kayu bundar sebanyak 566 sortimen kayu bundar $(56,39 \%)$ yang mengalami cacat, sedangkan cacat keseluruhan paling sedikit yaitu jenis cacat lubang gerek besar (Lgb) dengan jumlah pohon sebanyak 2 pohon $(2,22 \%)$ dan sortimen kayu bundar sebanyak 3 sortimen kayu bundar (0,30\%) yang mengalami cacat.

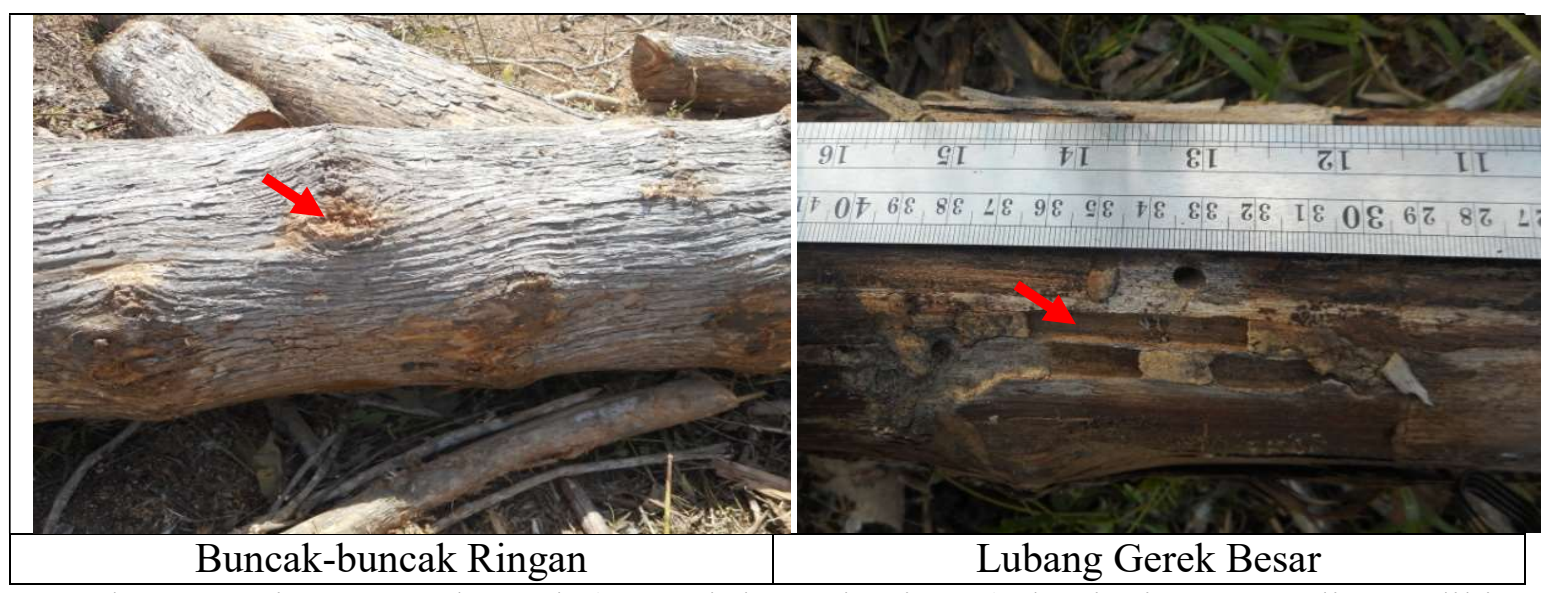

Gambar 1. Jenis cacat terbanyak (Buncak-buncak Ringan) dan jenis cacat paling sedikit (Lubang Gerek Besar) kayu bulat jati (Tectona grandis Linn.F.) pada areal pemanenan di KPH Jember (The most types of defects (buncak-buncak light) and little types of defects (big hole gerek) of teak (Tectona grandis Linn. F.) logs in the harvesting area in KPH Jember) 
Mutu kayu bulat jati merupakan kemampuan kegunaan kayu bulat jati untuk tujuan tertentu berdasarkan karakteristik yang dimilikinya (BSN, 2010a). Mutu kayu dihitung setelah pengukuran kayu bulat jati dengan ketentuan hasil mutu berdasarkan cacat yang paling berat atau terparah. Pengukuran mutu kayu mengacu pada tabel syarat mutu sortimen kayu bundar pada SNI 7535.1:2010 (BSN, 2010c). Hasil dari pengukuran 90 pohon dapat dilihat pada Tabel 2.

Tabel 2. Mutu Kayu Bulat Jati (Tectona grandis Linn.F.) pada Areal Pemanenan di KPH Jember (Quality of Teak (Tectona grandis Linn. F.) Logs in the Harvesting Area in KPH Jember)

\begin{tabular}{|c|c|c|c|c|c|c|}
\hline No & $\begin{array}{c}\text { Kelas } \\
\text { Sortimen } \\
\text { Kayu } \\
\text { Bundar }\end{array}$ & Mutu & $\begin{array}{c}\text { Jumlah } \\
\text { Sampel } \\
\text { Sortimen } \\
\text { Kayu } \\
\text { Bundar }\end{array}$ & $\begin{array}{c}\text { Persentase } \\
\text { Sampel } \\
\text { Sortimen } \\
\text { Kayu } \\
\text { Bundar }\end{array}$ & $\begin{array}{c}\text { Jumlah } \\
\text { Pohon } \\
\text { Sampel }\end{array}$ & $\begin{array}{c}\text { Persentase } \\
\text { Pohon } \\
\text { Sampel }\end{array}$ \\
\hline \multirow{7}{*}{1} & \multirow{7}{*}{ AIII } & $\mathrm{U}$ & 0 & 0,00 & 0 & 0,00 \\
\hline & & $\mathrm{P}$ & 10 & 1,01 & 9 & 10,00 \\
\hline & & D & 62 & 6,29 & 42 & 46,67 \\
\hline & & $\mathrm{T}$ & 55 & 5,58 & 41 & 45,56 \\
\hline & & $\mathrm{M}$ & 30 & 3,04 & 26 & 28,89 \\
\hline & & L & 30 & 3,04 & 27 & 30,00 \\
\hline & & BKR & 2 & 0,20 & 2 & 2,22 \\
\hline \multirow[t]{5}{*}{2} & \multirow{5}{*}{ AII } & $\mathrm{P}$ & 5 & 0,51 & 5 & 5,56 \\
\hline & & D & 44 & 4,46 & 30 & 33,33 \\
\hline & & $\mathrm{T}$ & 114 & 11,56 & 65 & 72,22 \\
\hline & & M & 176 & 17,85 & 75 & 83,33 \\
\hline & & BKR & 30 & 3,04 & 13 & 14,44 \\
\hline \multirow[t]{5}{*}{3} & \multirow{5}{*}{ AIII } & $\mathrm{P}$ & 19 & 1,93 & 17 & 18,89 \\
\hline & & D & 87 & 8,82 & 48 & 53,33 \\
\hline & & $\mathrm{T}$ & 119 & 12,07 & 60 & 66,67 \\
\hline & & M & 196 & 19,88 & 74 & 82,22 \\
\hline & & BKR & 7 & 0,71 & 4 & 4,44 \\
\hline
\end{tabular}

Keterangan:

$\begin{array}{llll}\mathrm{U} & =\text { Utama } & \mathrm{M} & =\text { Ke-empat } \\ \mathrm{P} & =\text { Pertama } & \mathrm{L} & =\text { Ke-lima } \\ \mathrm{D} & =\text { ke-dua } & \mathrm{BKR} & =\text { Bakar } \\ \mathrm{T} & =\text { Ke-tiga } & & \end{array}$

Kesimpulan

1. Berdasarkan hasil penelitian dilapangan mengenai cacat kayu bulat jati (Tectona grandis Linn.F.) pada areal pemanenan di $\mathrm{KPH}$ Jember berhasil diidentifikasi sebanyak 90 pohon dengan jumlah sortimen sebanyak 986 sortimen.
2. Cacat yang ditemukan sebanyak 23 jenis cacat baik itu cacat bentuk, cacat pada badan, maupun cacat pada bontos.

3. Jenis cacat pada cacat bentuk ada 5 jenis cacat yaitu cacat kelurusan, cacat kesilindrisan, cacat kebundaran, cacat alur,dan cacat arah serat. Jenis cacat pada cacat badan 
ada 10 jenis cacat yaitu cacat ingeringer, cacat buncak-buncak, cacat lubang gerek, cacat pecah, cacat gerowong di badan, cacat mata kayu, cacat benjolan, cacat lengar, cacat pecah banting, dan pecah slemper, sedangkan pada cacat bontos ada 8 jenis cacat yaitu cacat pecah bontos, cacat teras rapuh, cacat teras busuk, cacat gerowong, cacat gubal, cacat pakah, cacat gabeng, dan cacat kunus.

4. Hasil perhitungan cacat keseluruhan jenis cacat yang paling banyak ditemukan adalah cacat buncakbuncak ringan dengan jumlah pohon sebanyak 89 pohon $(98,89 \%)$ dan sortimen sebanyak 566 sortimen $(56,39 \%)$ yang mengalami cacat, sedangkan cacat keseluruhan paling sedikit yaitu jenis cacat lubang gerek besar ( $\mathrm{Lgb}$ ) dengan jumlah pohon sebanyak 2 pohon $(2,22 \%)$ dan sortimen sebanyak 3 sortimen $(0,30 \%)$ yang mengalami cacat.

\section{Saran}

Perlu adanya tindakan silvikultur dan penelitian lebih lanjut mengenai cacat pada kayu bulat jati (Tectona grandis.Linn.F) terutama cacat yang paling banyak ditemukan yaitu cacat buncak-buncak ringan agar volume cacat dapat ditekan sehingga mampu didapatkan kualitas kayu jati yang lebih baik dan bernilai tinggi.

\section{DAFTAR PUSTAKA}

Badan Standarisasi Nasional [BSN]. 2010(a). SNI 7533.1-2010. Kayu Bundar- Bagian 1: Istilah dan Definisi. Bogor : BSN

Badan Standarisasi Nasional [BSN]. 2010(b). SNI 7534.2-2010. Kayu

Bundar Daun Lebar-Bagian 2:Cara Uji : BSN

Badan Standarisasi Nasional [BSN]. 2010(c). SNI 7535.1-2010. Klasifikasi, persyaratan dan penandaan Bagian 1:Cara Uji : BSN

Badan Standarisasi Nasional [BSN]. 2010(d). SNI 7535.2-2010. Kayu Bundar Jenis Jati-Bagian 2 : Cara Uji. Bogor : BSN

Fraenkel, J.R. and Wallen, N.E. (1993). How to Design and Evaluate Research in Education. Singapura: McGraw-Hill Inc.

Habibi M, dan Imam Buchori. 2013. Model Spasial Kerentanan Sosial Ekonomi dan Kelembagaan Terhadap Bencana Gunung Merapi. Jurnal Teknik PWK, Volume 2 Nomor 12013.

Sugiyono. 2003. Statistika untuk Penelitian. Bandung: CV Alfabeta.

Sumarna Y. 2001. Budi Daya Jati. Jakarta: Penebar Swadaya.

Umarella U, dan Sedek K. 2011. Inventarisasi Hama pada Areal Tanaman Jati di Desa Liang Kecamatan Salahutu. Jurnal Bimafika, 2011,3， 235-238. Fakultas Kehutanan, Universitas Darussalam, Ambon. 